\title{
Impact of future land use and land cover change on temperature projections over East Asia
}

\author{
Xiaorui Niu ${ }^{1,2} \cdot$ Jianping Tang ${ }^{1,2} \cdot$ Shuyu Wang ${ }^{1,2} \odot \cdot$ Congbin $\mathrm{Fu}^{1,2}$
}

Received: 17 February 2018 / Accepted: 31 October 2018 / Published online: 7 November 2018

(c) The Author(s) 2018

\begin{abstract}
To assess the influence of future land use and land cover change (LULCC) on temperature projections over East Asia, and quantify its contribution relative to the increased greenhouse gas (GHG), two simulations, with and without LULCC, are performed by 4th regional climate model (RegCM4) driven by two global climate models for the year 2041-2060 under the Representative Concentration Pathway4.5 (RCP4.5) scenario. Results show that LULCC induces about the changes of $0.1-0.3{ }^{\circ} \mathrm{C}$ in surface air temperature over areas undergoing the conversion between forest and crop with clear regionality and seasonality. The responses of extreme temperature are more sensitive to LULCC than those of mean temperature, especially for the daily minimum temperature (Tmin)-related indices. Disagreements in the temperature responses between the two models are simulated during most of the years, particularly over east China during summer. Such uncertainties can be explained by the diversity responses of available energy, which is related to large scale atmospheric circulations produced by the RCM. The extent of LULCC can determine both the magnitude and sign of changes in temperature. LULCC-related changes of Tmax and Tmin can be as large as $25 \%$ of those by GHG. LULCC contributes less than $10 \%$ to the total projected warming under RCP4.5 when averaged over sub-regions but can reaches up to about $30 \%$ on local scales. Those results highlight the important role of LULCC in projecting the regional to local scale temperature changes, and emphasize the necessity of including LULCC forcing in future regional modeling studies.
\end{abstract}

Keywords Land use/land cover change (LULCC) $\cdot$ RegCM4 $\cdot$ Temperature $\cdot$ Uncertainty

\section{Introduction}

Extensive land use/land cover changes (LULCC) have been noticed over the past several centuries, primarily through the conversion from natural ecosystems to agricultural areas (Hurtt et al. 2011). Several studies using observed and modeled data have demonstrated the effects of LULCC on temperature and precipitation (Peng et al. 2014; Xu et al. 2015; Wang et al. 2018), and recommended the LULCC as an

Electronic supplementary material The online version of this article (https://doi.org/10.1007/s00382-018-4525-4) contains supplementary material, which is available to authorized users.

Shuyu Wang

wsy@nju.edu.cn

1 Institute for Climate and Global Change Research and School of Atmospheric Sciences, Nanjing University, 163 Xianlin Road, Nanjing, China

2 Jiangsu Collaborative Innovation Center for Climate Change, Nanjing, China important climate forcing. At regional scales, the impacts of LULCC on temperature and some hydrometeorological variables can be as strong as those of atmospheric $\mathrm{CO}_{2}$ concentrations (Zhao and Pitman 2002; De Nobletducoudré et al. 2012) or other large-scale forcings (Findell et al. 2008). Therefore, the climatic consequence of LULCC is a key scientific issue in climate change research, and has to be considered to fully assess future climate changes, especially in regions that are expected to experience extensive land cover changes in the future.

The impacts of LULCC on climate can be expressed in terms of different biogeochemical and biogeophysical processes. Biogeochemical effects alter the carbon cycles via the emissions or absorptions of atmospheric greenhouse gasses, which, in turn, affects the climate system (Claussen et al. 2001; Arora and Boer 2010). Biogeophysical mechanisms can affect the surface energy and water cycles by modifying the physical characteristics of the land surface (Pitman et al. 2009; Davin and Nobletducoudré 2010). Previous studies have indicated that the impacts of LULCC on temperature 
are regionally and seasonally dependent and exhibit large uncertainties in both sign and magnitude (Pitman et al. 2009; De Nobletducoudré et al. 2012). For example, Christidis et al. (2013) found that deforestation over Eastern North America led to a significant cooling of the warm daily temperature extremes, while warmings of both the maximum and minimum temperatures in June over Eastern United States were shown by Strack et al. (2008) when forest areas were replaced by crops. Some models simulate a regional cooling caused by midlatitude deforestation and attribute this cooling to changes in albedo (Govindasamy et al. 2001; Matthews et al. 2003), while other models predict a warmer condition resulting from changes in the partitioning between sensible and latent heat flux (Findell et al. 2007, 2008). Such discrepancies in temperature responses among models suggest that there is an urgent need for thorough and systematic research to quantify the effects of LULCC, especially at regional scales.

East Asia is one of regions with the most human-activity in the world and has experienced dramatic expansions of croplands in recent years (Goldewijk 2001). In reaction to this phenomenon, numerous research efforts have been devoted to analyzing the linkages between the LULCC and climate change over East Asia (Fu and Yuan 2001; Zhang et al. 2009; Xu et al. 2015), and the results show that the temperature extremes are very sensitive to LULCC (Wen et al. 2013; Li et al. 2017). As the relationships between LULCC and temperature extremes change with increasing greenhouse gas (GHG) forcing (Pitman et al. 2011), knowledge of the role of LULCC in the projected temperature extremes over East Asia is still limited (Hua et al. 2015; Quesada et al. 2017). In particular, recent studies have demonstrated the importance of including projections of land cover change in simulations of future climates (Feddema et al. 2005; Lawrence et al. 2016). Therefore, a careful assessment will be necessary to assess the future impacts of LULCC on projected changes in temperature extremes over East Asia and quantify its effects relative to other forcings.

Contrary to previous studies focusing on global climate models (GCM) or idealized land cover change scenarios, regional climate models (RCMs), which provide useful information at regional scales (Fu et al. 2005; Pal et al. 2007), are used in this study to address the influence of LULCC on future climate projections. We use simulations from a regional climate model (RegCM4) driven by two GCMs to access the effects of a plausible future scenario of LULCC for the near future period over East Asia under the representative concentration pathway 4.5 (RCP4.5) and quantify the contributions of LULCC to climate projections.

This paper is organized as follows. The descriptions of models, the land use datasets and the experimental design are given in Sect. 2. Section 3 provides the likely changes in temperature extremes over East Asia attributed to future LULCC. In Sect. 4, we disentangle the temperature response among regions, models and the extent of LULCC, and also discuss the contribution of future LULCC to the temperature projections. Section 5 presents our conclusion with discussion.

\section{Model description, experimental design and extreme indices}

\subsection{Model configuration and land use datasets}

RegCM was developed by the Abdus Salam International Center for Theoretical Physics (ICTP) and has undergone major updates in 2010 (RegCM4, Giorgi et al. 2012). This model has been widely used in regional climate research, and can reasonably capture the mean and extreme climate characteristics over East Asia (Gao et al. 2006; Zou and Zhou 2016). In this study, we adopt the latest version of this model, RegCM4, to investigate future effects of LULCC over East Asia. The main physical options used in this study include the National Center for Atmospheric Research (NCAR) Community Climate Model version 3 (CCM3) radiation scheme (Kiehl et al. 1993), the Massachusetts Institute of Technology (MIT)-Emanuel cumulus scheme (Emanuel 1991), the Holtslag planetary boundary layer scheme (Holtslag and Boville 1993) and the subgrid explicit moisture (SUBEX) scheme for large-scale clouds and precipitation (Pal et al. 2000). The Community Land Model version 3.5 (CLM; Oleson et al. 2008) is adopted for the land surface model, with 15 plant functional types (PFT), bare ground, lakes and glaciers (Dai et al. 2003).

The lateral boundary conditions (LBCs) affect not only the simulation of climatic conditions (Niu et al. 2015; Hui et al. 2018) but also the simulated climate change signals (Yu and Wang 2014; Saini et al. 2015). Considering that the climate responses to LULCC in RCM simulations may depend on the LBCs, we choose two GCMs, including the Institute Pierre Simon Laplace-Climate Model version 5A (IPSLCM5A) (Dufresne et al. 2013) and EC-EARTH (Hazeleger et al. 2010), to provide the initial and LBCs for RegCM4 in this study. The two GCMs basically reproduce the observed spatial distributions of temperature and precipitation over East Asia, although they underestimate the temperature and overestimate the precipitation over most areas. In the future, the GCM of IPSL-CM5A projects much warmer than ECEARTH under RCP4.5, and inconsistent changes in precipitation projections between the two models are generated over Northwest China and Sichuan Basin (Hui et al. 2017; 2018).

The land cover datasets with $0.5^{\circ}$ resolution are generated by land-use harmonization (LUH) project (Hurtt et al, 2011), which provides the annual variations of land cover types and annual land use transitions for the periods of 1500-2100 (http://luh.umd.edu/). In our study, two land cover datasets 
for the years 1990 and 2050 are used to represent the present and future land cover conditions. Figure 1 shows the fractional changes in forest, crop and grass lands in 2050 with reference to the coverage in 1990, which are calculated as the sums of all types of forests, crops and grasses, respectively. Agricultural expansion will occur over most of China at the expense of forests and grasses, while over central Russia and northern India, higher percentages of croplands will converted to forests and grasses in the future.

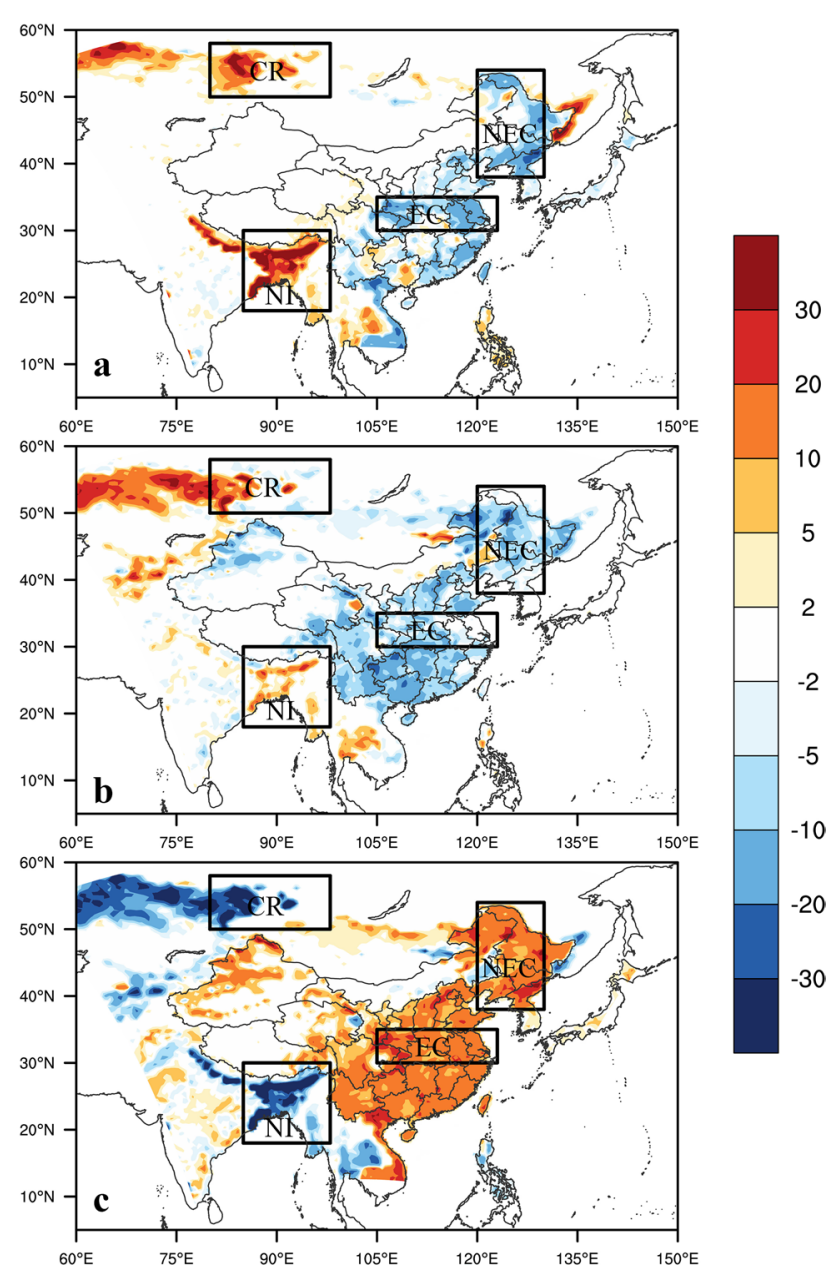

Fig. 1 Changes in plant functional types (unit: \%) between future and present land cover (LU2050-LU1990) over East Asia: a forest, b grass and c crop. Four black boxes are used to identify the subregions with substantial LULCC: Northeast China, East China, Central Russia and northern India

\subsection{Experimental setup}

We designed three experiments focusing on the impacts of future LULCC and the contributions of LULCC to future climate projections (Table 1). The first experiment, named RF, spans the 1979-2000, and the land cover in this experiment remains constant with the configuration in 1990 . RF is performed as a baseline simulation for comparisons. Two sets of future climate simulations are carried out. One is RCP45, which lasts from 2039 to 2060 using the land cover patterns of 2050 under the RCP 4.5 scenario; the other is L2A 45, which is the same run with identical RCP45 atmospheric forcing while keeping the land cover patterns constant with the present conditions.

All simulations are integrated over East Asia at a resolution of $50 \mathrm{~km}$ (Fig. 1). The simulation domain consists of $124 \times 112$ grid points, with the center located at $36.5^{\circ} \mathrm{N}$, $102^{\circ} \mathrm{E}$. All simulations run for 22 years, and the last 20 years of simulations are analyzed in this study. The performances of the RegCM4 driven by the two GCMs in simulating the climatology of extreme temperature indices are good (Hui et al. 2017). Thus, we use the results from RegCM4 to explore the potential impacts of future LULCC on temperature extremes over East Asia.

In this study, the differences between the RCP45 and L2A45 simulations (RCP45-L2A45) are considered as the biophysical effects of future LULCC, and the contributions of future LULCC to climate projections are calculated by using the effects of future LULCC relative to future projections with all forcings ((RCP45-L2A45)/(RCP45-RF)). The future LULCC mainly occurs over four subregions (Fig. 1a), that is, northeast China (NEC, $\left.38-54^{\circ} \mathrm{N}, 120-130^{\circ} \mathrm{E}\right)$, east China $\left(\mathrm{EC}, 30-35^{\circ} \mathrm{N}, 105-123^{\circ} \mathrm{E}\right)$, central Russia (CR, $\left.50-58^{\circ} \mathrm{N}, 80-98^{\circ} \mathrm{E}\right)$ and northern India (NI, $18-30^{\circ} \mathrm{N}$, $85-98^{\circ} \mathrm{E}$ ). Thus, this study focuses on these regions to investigate the temperature responses to the conversions between forests and crops.

\subsection{Temperature extreme indices}

Eight out of the 27 climate indices recommended by the CCI/CLIVAR/JCOMM Expert Team on Climate Change Detection and Indices (ETCCDI, Alexander et al. 2006) are selected in this study to represent temperature extremes. These indices including four absolute indices and four
Table 1 List of model experiments

\begin{tabular}{llll}
\hline Experiment name & $\begin{array}{l}\text { Year of vegetation } \\
\text { map }\end{array}$ & Atmospheric GHGs & Simulated years \\
\hline RF & 1990 & & $1979-2000$ \\
RCP45 & 2050 & Transient scenario(RCP45) & $2039-2060$ \\
L2A45 & 1990 & Transient scenario(RCP45) & $2039-2060$ \\
\hline
\end{tabular}


percentile-based indices can assess the changes in intensity and frequency of extreme temperature events, respectively (Table 2). The period of 1981-2000 in the RF experiment is used as the reference period to obtain the frequency indices.

\section{Results}

\subsection{Surface air temperature response to LULCC}

Unlike greenhouse gasses which generate irrebuttable warming effects on the global and regional climate, the effects of the future LULCC on the mean temperature (T2m) in IPSL-RegCM4 vary regionally and seasonally, with stronger responses in summer (Fig. 2a, b). Overall, the coolings and warmings from different land cover conversion cancel each other, which finally lead to negligible responses in seasonal $\mathrm{T} 2 \mathrm{~m}\left(-0.01\right.$ to $\left.0.01{ }^{\circ} \mathrm{C}\right)$ over East Asia. However, local warming or cooling reaching up to $0.1-0.3{ }^{\circ} \mathrm{C}$ is directly associated with deforestation or afforestation. Significant cooling is found over NI in both seasons due to the conversion of agricultural land to forest. This cooling effect is associated with the domination of the impacts of evapotranspiration and surface roughness, although albedo decrease partly offsets the cooling effect (Davin and Nobletducoudré 2010). However, over higher latitudes, changes in $\mathrm{T} 2 \mathrm{~m}$ due to vegetation feedback vary from season to season. For instance, the seasonality of T2m changes over CR manifests a cooling effect in summer and warming effect in winter because of afforestation. The deforestation over NEC generates increased temperatures in summer and decreased temperatures in winter.

Different responses of the maximum temperature (Tmax) between higher-latitude areas and lower-latitude areas are simulated (Fig. 2c, d) due to crops are replaced by forests, with a warming effect over higher-latitude areas and a cooling effect over lower-latitude areas in all seasons. This phenomenon may be caused by different dominant bio-geophysical processes between two regions. A decrease of approximately $0.1-0.3{ }^{\circ} \mathrm{C}$ in $\mathrm{Tmax}$ is found over the deforestation areas in China. The spatial patterns of the changes in the minimum temperature (Tmin) resemble those in T2m (Fig. 2e, f), suggesting that the nighttime temperature plays a more important role than the daytime temperature in determining $\mathrm{T} 2 \mathrm{~m}$. The magnitudes of the Tmin changes are larger and more significant than the responses of Tmax, especially during summer. Most of the areas to the north of $35^{\circ} \mathrm{N}$ exhibit opposite signs in Tmin between summer and winter. For example, significant warming of $0.3-0.5{ }^{\circ} \mathrm{C}$ in Tmin during summer is found over areas of NEC that underwent deforestation, while a slight cooling effect occurs in there during winter. As short vegetation can be covered by snow during winter, the difference in surface albedo between the deciduous/evergreen forest and the crops is substantial, which would result in a warming effect when crops or grasses are replaced by forests (Alexandru and Sushama 2016).

The above results show that Tmin is more sensitive to LULCC than Tmax. Thus, the diurnal temperature range (DTR) is strongly affected by LULCC (figure not shown). The DTR is largely reduced (approximately $0.5-1{ }^{\circ} \mathrm{C}$ ) in summer over deforestation areas in China and significantly increased over CR, where crops are replaced by forests. During winter, significant changes in the DTR are mostly detected over the areas south of $35^{\circ} \mathrm{N}$ due to LULCC, such as the increase over northeast India and decrease over southeast China.

As most significant temperature responses occur over the areas with conversions between forests and crops, and those responses show seasonal variation characteristics, we select four regions (Fig. 1a) and analyze the seasonal cycle of the changes in temperature indices to better understand the time dependence of temperature changes induced by LULCC (Fig. 3). The seasonal cycle of the simulated changes in $\mathrm{T} 2 \mathrm{~m}$ basically follows that of Tmin, no matter the sign of the tree fraction change. However, each region has its own regional characteristics. For example, the forest warming over CR in winter persists through May, with the largest changes (approximately $0.14{ }^{\circ} \mathrm{C}$ ) occurring in March. Over NI, the simulations show a cooling signal with afforestation throughout the year with little seasonality. The roles of the forests over NEC and EC are similar with those over CR and NI, respectively. For Tmax, the forests generate
Table 2 The temperature extreme indices recommend by ETCCDI and used in this study

\begin{tabular}{llll}
\hline Type & Index name & Definition & Unit \\
\hline Intensity & TXx & Monthly maximum value of daily Tmax & ${ }^{\circ} \mathrm{C}$ \\
& TXn & Monthly minimum value of daily Tmax & ${ }^{\circ} \mathrm{C}$ \\
& TNn & Monthly minimum value of daily Tmin & ${ }^{\circ} \mathrm{C}$ \\
Frequency & TNx & Monthly maximum value of daily Tmin & ${ }^{\circ} \mathrm{C}$ \\
& TX90p & Number of days when Tmax $>90$ th percentile & Days/season \\
& TX10p & Number of days when Tmax $<10$ th percentile & Days/season \\
& TN90p & Number of days when Tmin $>90$ th percentile & Days/season \\
& TN10p & Number of days when Tmax $<10$ th percentile & Days/season \\
\hline
\end{tabular}



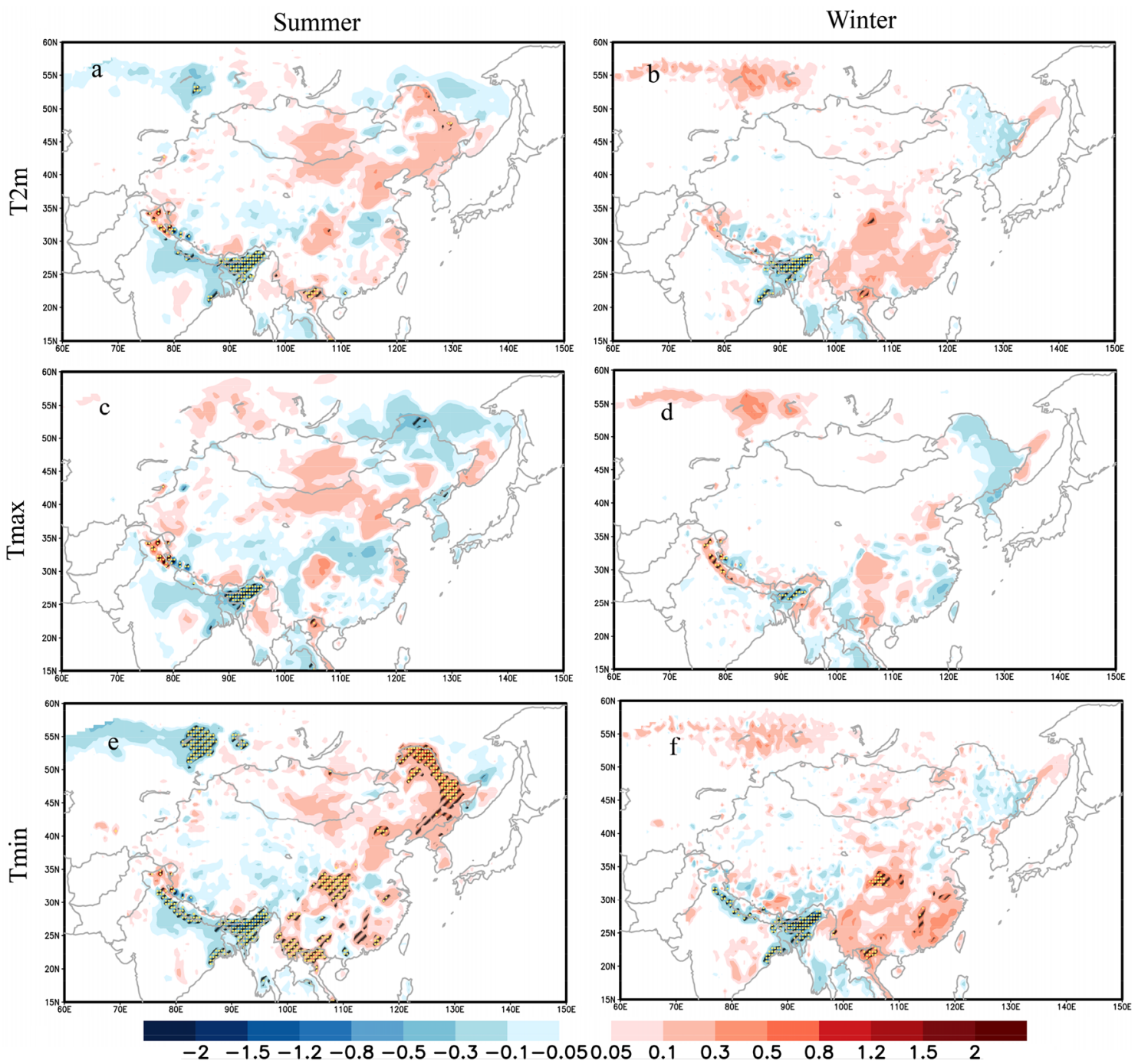

Fig. 2 Changes in $\mathrm{T} 2 \mathrm{~m}$ (unit: $\left.{ }^{\circ} \mathrm{C}, \mathbf{a}, \mathbf{b}\right)$, Tmax (unit: ${ }^{\circ} \mathrm{C}$; $\mathbf{c}, \mathbf{d}$ ) and Tmin (unit: ${ }^{\circ} \mathrm{C}$; e, f) due to future LULCC during summer (left column) and winter (right column) in IPSL-RegCM4. Note that yellow dots (black slash) denote significance at the $90 \%$ (80\%) confidence level

warming effects over CR, NEC and EC, while causing a cooling effect over NI. The largest response of Tmax to forest changes always occurs in summer over all regions except $\mathrm{CR}$, where the maximum increase (approximately $0.2^{\circ} \mathrm{C}$ ) occurs in April. The differences in the DTR are always positive throughout the year over the afforestation areas, and negative trends are present over the deforestation areas. The characteristics of the annual cycle of the DTR over NI are different from those in other regions, as this area shows the maximum increase in winter and minimum increase in summer.

These $\mathrm{T} 2 \mathrm{~m}$ responses in the future are broadly consistent with the analyses in the present, which built on overlapping satellite retrievals of surface radiometric temperature and of variations in forest cover (Alkama and Cescatti 2016; Findell et al. 2017). Their results show that a clear warming with deforestation is observed in the temperate zone and tropics, while in boreal zone in northern hemisphere winter, deforestation leads to a cooling signal which persists through April. Nevertheless, the responses of Tmax and Tmin are not in agreement with the observations. Such discrepancies may be related with different GHG scenarios, as scenarios with the same general direction of LULCC differ in their climatic effects (Brovkin et al. 2013). Additional sensitivity experiments should be designed to further investigate the underlying mechanisms responsible for the inconsistences.

\subsection{The response of extreme temperatures to LULCC}

Figure 4 depicts the effects of LULCC on the absolute temperature indices over East Asia by IPSL-RegCM4. Compared to the Tmax responses, the changes in the hottest daily 

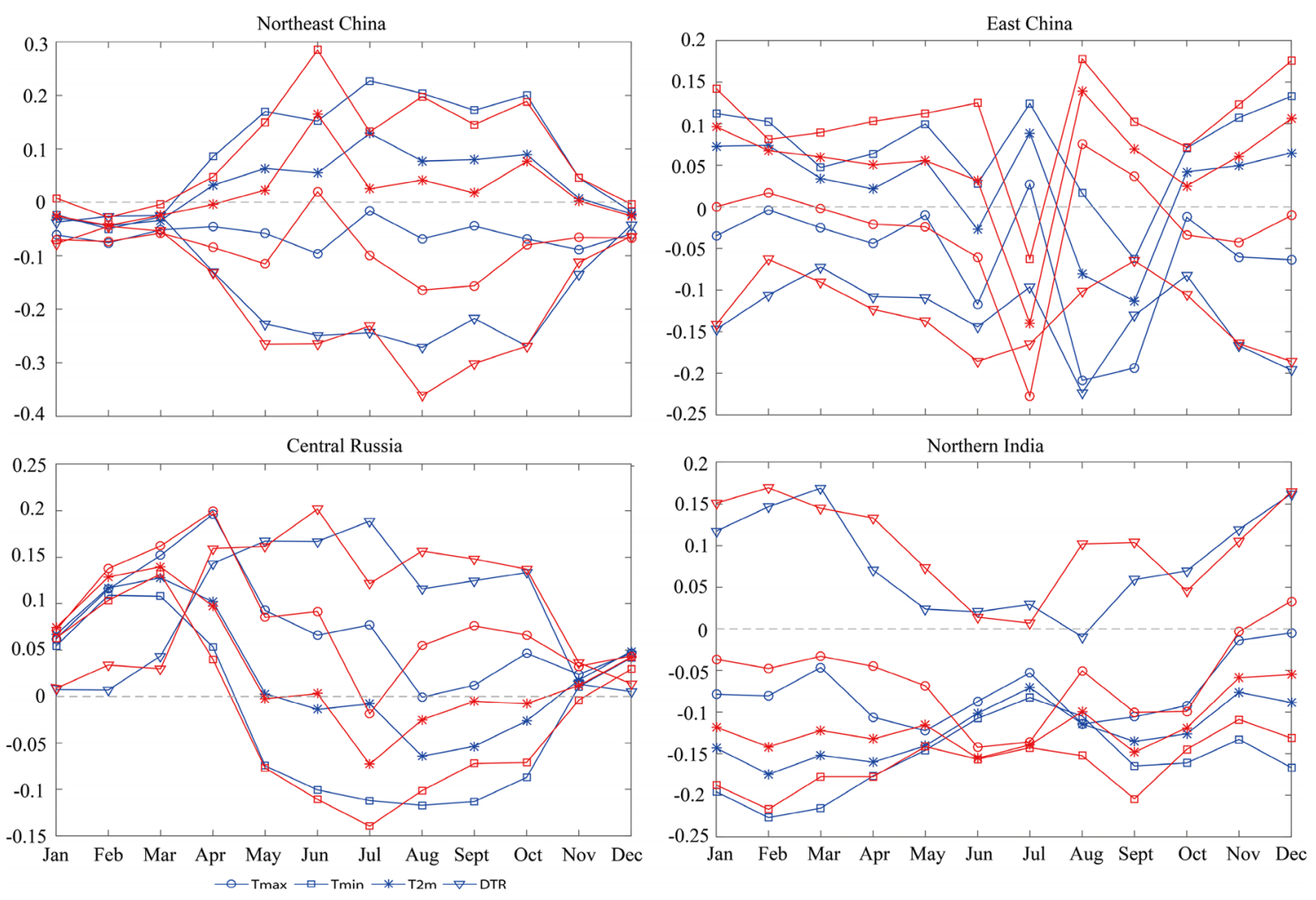

Fig. 3 Annual cycle of the LULCC-induced changes in Tmax (circle), Tmin (square), T2m (asterisk) and DTR (triangle) over four sub-regions. Red and blue lines represent IPSL-RegCM4 and EC-RegCM4, respectively

maximum temperature (TXx) and coldest daily maximum temperature (TXn) show similar spatial distributions but tend to be amplified in summer. For example, significant cooling (approximately $0.3-0.5{ }^{\circ} \mathrm{C}$ ) in TXx occurs during summer over most of the deforestation areas and NI. Compared to the responses of TXX to LULCC, changes in TXn are larger over NEC and CR during winter, while the changes are smaller over lower-latitude areas. Additionally, few areas with negligible LULCC are simulated to experience significant changes in TXn, such as approximately $0.5-0.8^{\circ}$ warming over areas located at $\left(37-42^{\circ} \mathrm{N}\right.$, $\left.100-110^{\circ} \mathrm{E}\right)$. Previous studies suggested that LULCC would affect large-scale circulations by modifying geopotential heights and atmospheric winds, and then alter temperature over other areas (Quesada and Arneth 2017).

The results for the coldest daily minimum temperature (TNn) and hottest daily minimum temperature (TNx) are also consistent with those for Tmin, with larger magnitudes in $\mathrm{TNn}$ and smaller in TNx (Fig. 4e-h). In detail, the responses of TNn to LULCC are approximately $0.5-0.8{ }^{\circ} \mathrm{C}$ over the regions north of $35^{\circ} \mathrm{N}$ during summer, larger than those over areas south of $35^{\circ} \mathrm{N}$ by about $0.2-0.5^{\circ} \mathrm{C}$. However, the effects of LULCC on TNn arestronger over lower latitudes during winter. The spatial distributions of changes in TNx resemble to those in $\mathrm{TNn}$, but with smaller magnitude.
The influences of LULCC on the frequencies of the percentile-based temperature indices, including TX90p, TX10p, TN90p and TN10p, are also present in Fig. 5. Clearly, the magnitudes of the changes in TX90p and TN90p are far larger than those in TX10p and TN10p, and the signs of the changes in the indices exceeding the 90th percentile are in contrast to those in the indices below the 10th percentile. In detail, LULCC broadly reduce the value of TX90p over East Asia, particularly over NEC and NI in summer (more than 2 days per season). During winter, a significant decrease in TX90p is simulated over only NI. Deforestation in summer leads to a substantial increase of approximately 5 days per season in TN90P but a decrease of up to 1-2 days per season in TN10p. However, significant influences of LULCC can be detected over only lowerlatitude regions during winter.

\section{Discussions}

Based on our results, we conclude that the impact of future LULCC is relatively larger for temperature extreme than that for the mean temperature projections. Moreover, the Tmin-related indices are more sensitive to LULCC than the Tmax-related indices, and the sensitivities of the 

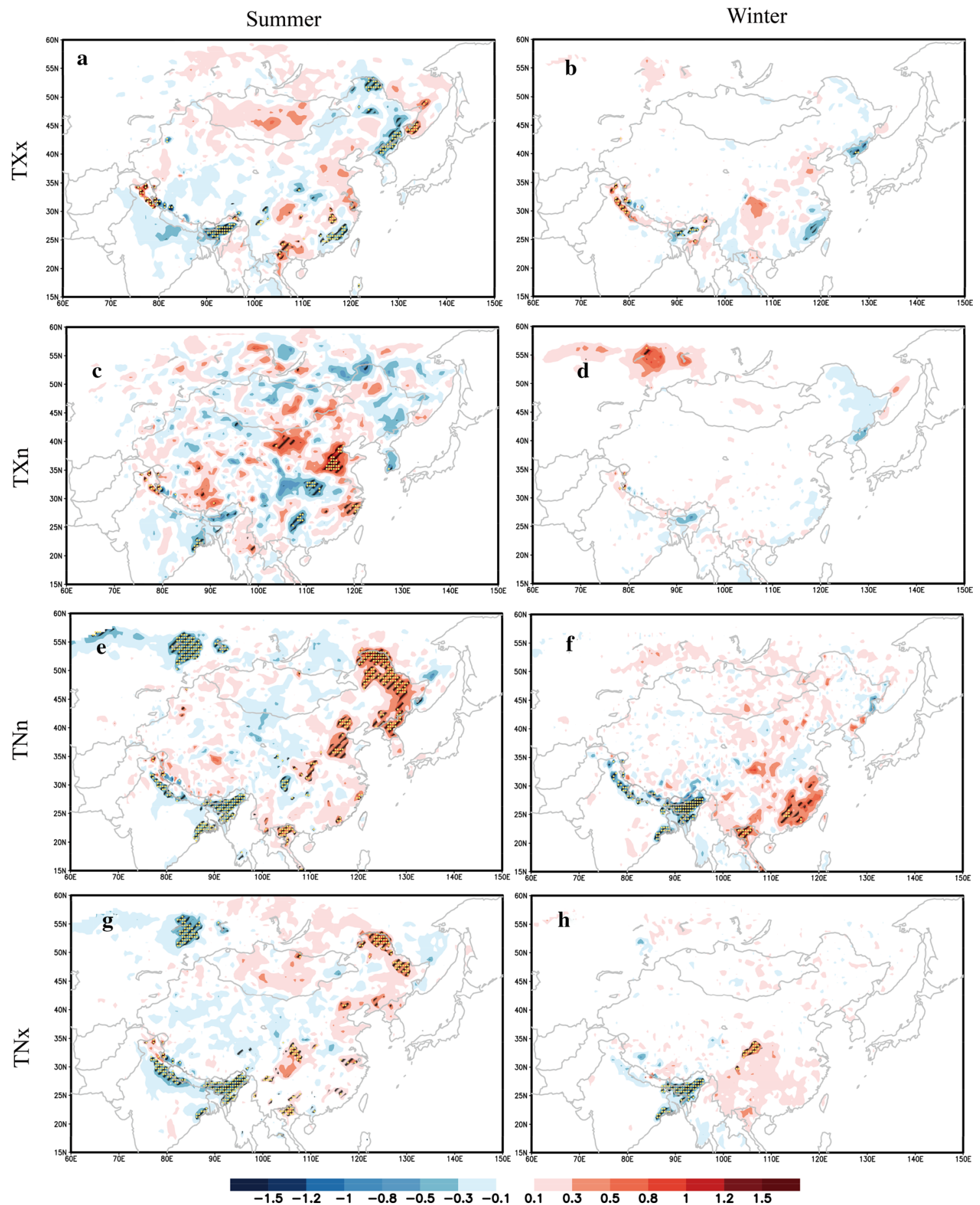

Fig. 4 Changes in the absolute temperature indices (unit: ${ }^{\circ} \mathrm{C}$; TXx: a, b; TXn: c, d; TNn: e, f; TNx: $\mathbf{g}, \mathbf{h}$ ) due to future LULCC during summer (left column) and winter(right column) in IPSL-RegCM4. Note

that yellow dots (black slash) denote significance at the $90 \%(80 \%)$ confidence level

temperature differ across regions. In this section, the possible mechanisms of changes in Tmax and Tmin and the influences of LBCs on temperature responses are discussed, and the contributions of LULCC to temperature projections are also presented.

\subsection{Controlling factors of temperature responses}

Previous studies have noted that the forests, which have lower albedos than other types of vegetation, absorb more incoming shortwave radiation and release it as sensible heat 
Summer
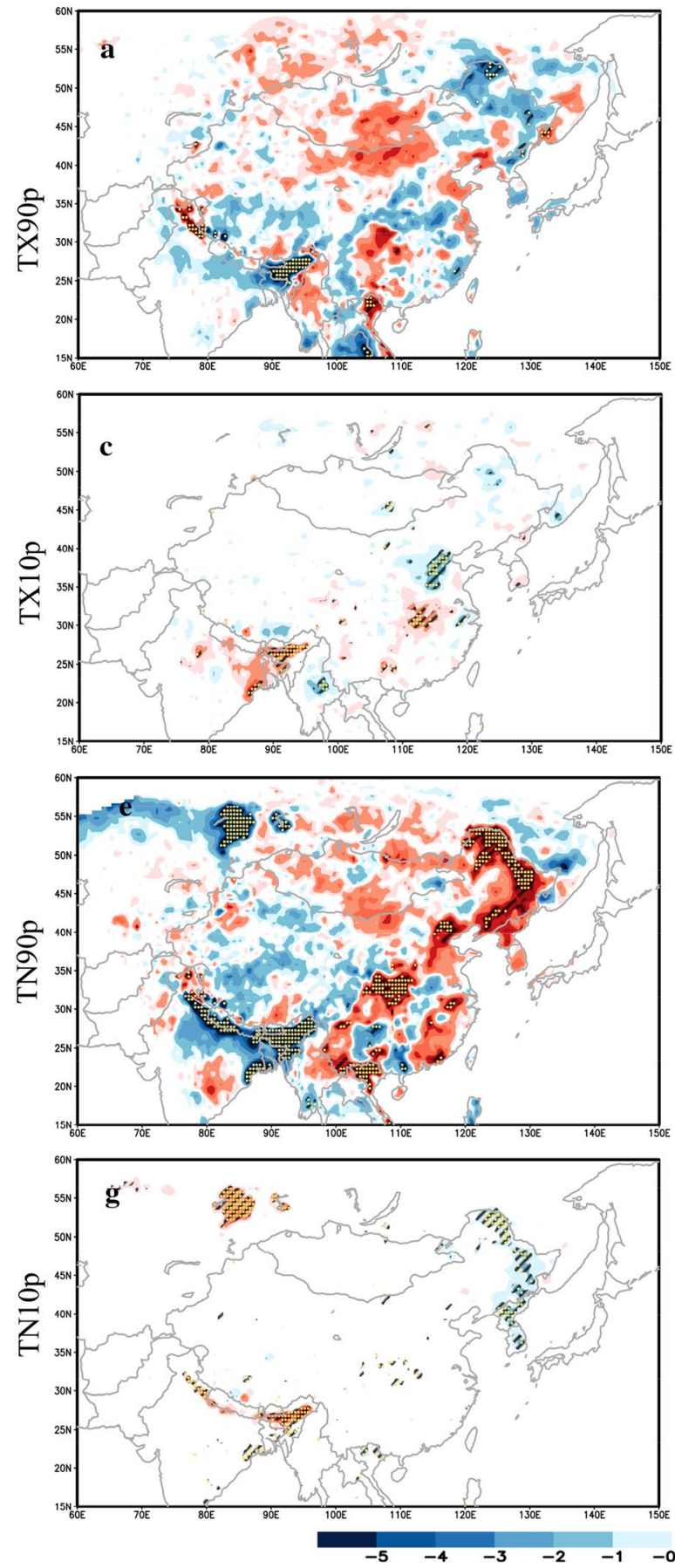

Fig. 5 Changes in the frequencies of the percentile-based temperature indices (unit: day; TX90p: a, b; TX10p: c, d; TN90p: e, f; TN10p: $\mathbf{g}, \mathbf{h}$ ) due to future LULCC during summer (left column) and

to warm the air temperature (Bala et al. 2007). On the other hand, forests can also obtain water from soil and release it back to the atmosphere through latent heat flux, resulting in a cooling effect (Feddema et al. 2005). Furthermore, the higher roughness of forests induces greater turbulence,
Winter
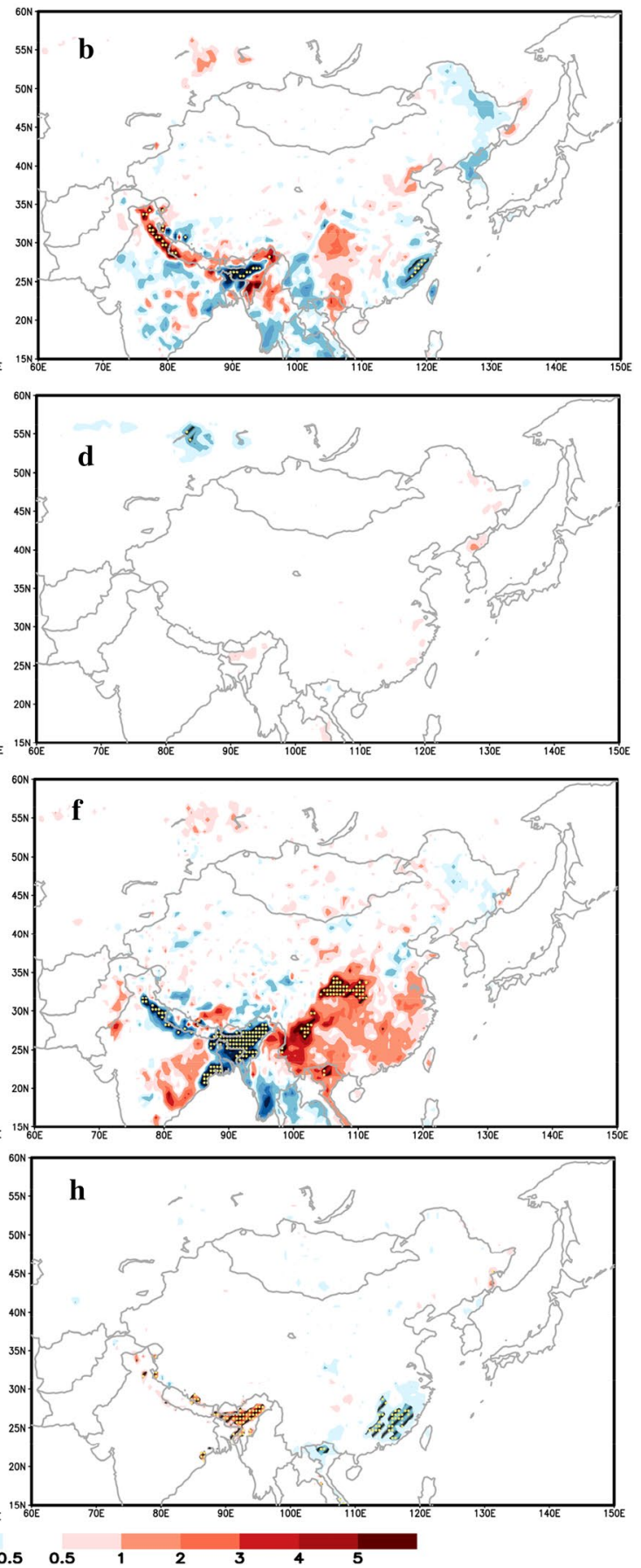

winter(right column) in IPSL-RegCM4. Note that yellow dots (black slash) denote significance at the $90 \%(80 \%)$ confidence level

which increases the capacity of the land to exchange energy with the atmosphere and potentially enhances convection, cloud cover and rainfall (Alexandru and Sushama 2016).

LULCC modifies the surface energy balance by changing the biogeophysical processes mentioned above, and the 
interactions among these mechanisms vary with latitude. Thus, to investigate the regional differences in air temperature changes induced by LULCC, a decomposed temperature metric proposed by Juang et al. (2007) is employed in this study. This method, which has been widely used to attribute temperature changes to surface energy components (Boisier et al. 2012; Xu et al. 2015; Li et al. 2017), is based on the land surface energy balance equation:

$Q_{A S R}+Q_{L d}-Q_{L u}=Q_{S H}+Q_{L H}+Q_{G}$

where all fluxes are in watts per square meter, $Q_{A S R}$ refers to the absorbed solar radiation at the land surface (ASR); $Q_{L d}$ indicates the surface downward longwave radiation (DLR); $Q_{L u}$ is the surface upward longwave radiation; $Q_{S H}, Q_{L H}$ and $Q_{G}$ represent the sensible heat flux (SH), latent heat flux (LH) and ground heat flux (GHF), respectively. After introducing the Stefan-Boltzmann law and Taylor series expansion, Eq. (1) can be computed as follows:

$\Delta T=\frac{1}{4} \sigma^{-\frac{1}{4}}{\overline{Q_{L u_{-} 1990}}}^{-\frac{3}{4}}\left(\Delta Q_{A S R}+\Delta Q_{L d}-\Delta Q_{S H}-\Delta Q_{L H}-\Delta Q_{G}\right)$

where $\sigma$ and $\mathrm{T}$ refer to the Stefan-Boltzmann constant $\left(5.67 \times 10^{-8} \mathrm{Wm}^{-2} \mathrm{~K}^{-4}\right)$ and land surface temperature, respectively, $Q_{L L_{-} 1990}$ refers to the mean value of the upward longwave radiation in the L2A45 simulation. Consequently, the factors that are responsible for the changes in the Tmax (Tmin) can be detected by analyzing the terms on the righthand side of Eq. (2) and examining the responses of surface energy fluxes during the daytime (nighttime). Detailed information about this method can be found in the appendix of Li et al. (2017).

Figure 6 shows the changes in surface energy components induced by LULCC. In the figure, the SH, LH and GHF are multiplied by -1 to provide a convenient interpretation. During the daytime, the ASR, which is closely related to albedo, tends to decrease over the deforestation areas and increase over the afforestation areas, and these trends are accompanied by cooling effect over NEC and $\mathrm{EC}$ and warming effect over CR and NI. The reductions in the DLR induced by LULCC are simulated over both deforested and reforested areas. Thus, the sum of ASR and DLR, which is considered as the available energy (ASR + DLR) at the land surface, favors cool temperatures over deforested areas and warm temperatures over reforested areas. For the turbulent fluxes $(\mathrm{SH}+\mathrm{LH})$, the changes show consistent trends with those for available energy, and their influence on temperature compensates for the effect of the available energy. Compared to the change in $\mathrm{SH}$, the response of $\mathrm{LH}$ is relatively weak over the four sub-regions, with the exception over NI. The enhancement in $\mathrm{LH}$ (about $4-6 \mathrm{~W} / \mathrm{m}^{-2}$ ), which is the largest change among the five components over NI, is the main factor that cools the surface. The simulated changes in GHF are used to cool the deforestation areas and warm the afforestation areas. Finally, the sum of the five components (Sum) shows a negative trend over the four regions, which favors a decrease in Tmax. The nonsignificant change in Tmax (Table 3) over CR may be explained by the LULCCinduced increase in $\mathrm{SH}$, which accentuate the energy transfer of energy from the ground to the atmosphere and warm the air temperature (Xu et al. 2015).

As ASR can be neglected during the nighttime, Tmin is determined by other terms. Generally, the effects of the other four components at night are always opposite to those during the day, except for the DLR over afforested areas. The strongest response to LULCC among the four components at night is GHF, which may dominate the changes in Tmin over the four sub-regions. As is shown in Fig. 6, the diurnal cycle of GHF is enhanced over the deforested areas and dampened over the afforested areas, thereby reducing DTR over NEC and NC and increasing DTR over CR and NI. Deforestation leads to a direr soil condition (figures not shown), which is benefit effective heat transfer between the land surface and deeper soil, and increase the downward GHF during the daytime and the upward GHF at night (Xu et al. 2015). These mechanisms of LULCC-induced changes in DTR are also found over North Africa and global monsoon areas (Zhou et al. 2007; Notaro et al. 2011).

Clearly, the effect of LULCC on temperature can mostly be explained by the changes in surface energy fluxes. However, disadvantages still exist in the interpretation of the changes in Tmax and Tmin over some regions. For instance, the changes in daytime surface energy favor a decrease in Tmax over CR, while a small warming effect is simulated over there. Those unexpected responses can possibly be explained as follows: (1) the surface energy components have 3-h temporal resolutions, which is too coarse to diagnose the instantaneous variables of Tmax/Tmin; (2) the occurrence times of Tmax/Tmin may mismatch the times we selected in our study; (3) the climatic mean upward longwave radiation, which should be contained in the equation, is not considered in this study.

\subsection{The effect of the LBCs on the temperature response to LULCC}

Since the LBC that derived from GCMs is one of the uncertainty sources in the long-term simulation when using RCM, and can modulate the simulated climate change signal, it is helpful to understand the effect of the LBCs on the temperature response to LULCC by comparing the results between the two models. Compared to IPSL-RegCM4, similar spatial patterns of the temperature responses to LULCC are found in EC-RegCM4, but with different magnitude (Supplementary Fig. 1-3). The inter-model differences in temperature responses are more pronounced in summer than in other 


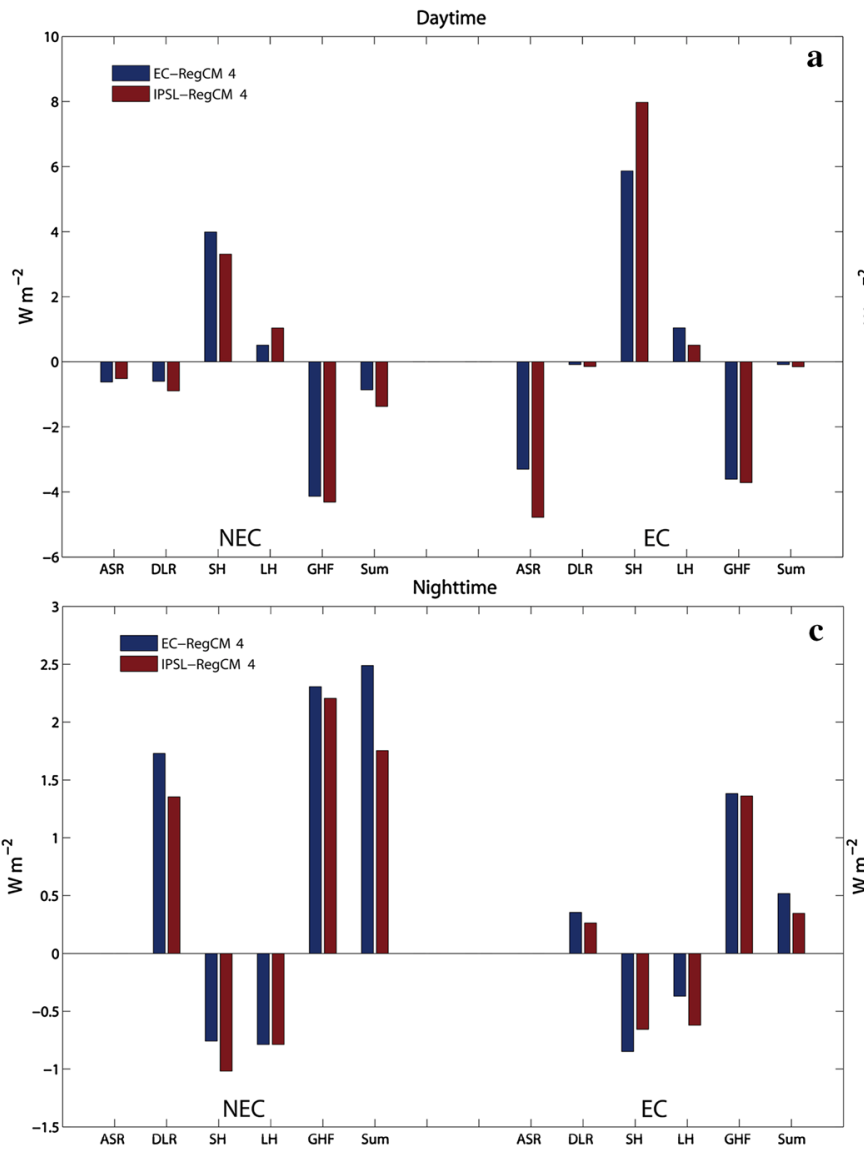

Fig. 6 Changes in the components of land surface energy (unit: $\mathrm{Wm}^{-2}$ ) induced by LULCC over four sub-regions during daytime and nighttime. ASR and DLR represent absorbed solar radiation and downward longwave radiation at surface, $\mathrm{SH}, \mathrm{LH}$ and GHF indicate sensible heat flux, latent heat flux and ground heat flux, respectively.

seasons over the four sub-regions, and the discrepancies are more common over EC than other regions (Fig. 4). For instance, the two models even simulate opposite changes of T2m over the summer months in EC. Such uncertainties mainly arise from the discrepancies in producing the largescale circulation by GCMs. Same LULCC under different large-scale circulation in RCM can trigger various precipitation changes, which largely control the impacts of LULCC on local temperatures, particularly in summer over the areas

Table 3 Four sub-regions averaged mean changes in Tmax and Tmin (unit: ${ }^{\circ}$ ) induced by LULCC

\begin{tabular}{rlrrrr}
\hline & & \multicolumn{1}{l}{ NEC } & \multicolumn{1}{l}{ EC } & \multicolumn{1}{l}{ CR } & \multicolumn{1}{l}{ NI } \\
\hline \multirow{2}{*}{ Tmax } & EC-RegCM4 & -0.06 & -0.10 & 0.05 & -0.09 \\
& IPSL-RegCM4 & -0.08 & -0.07 & 0.04 & -0.11 \\
\multirow{2}{*}{ Tmin } & EC-RegCM4 & 0.19 & 0.06 & -0.11 & -0.10 \\
& IPSL-RegCM4 & 0.21 & 0.08 & -0.12 & -0.15 \\
\hline
\end{tabular}

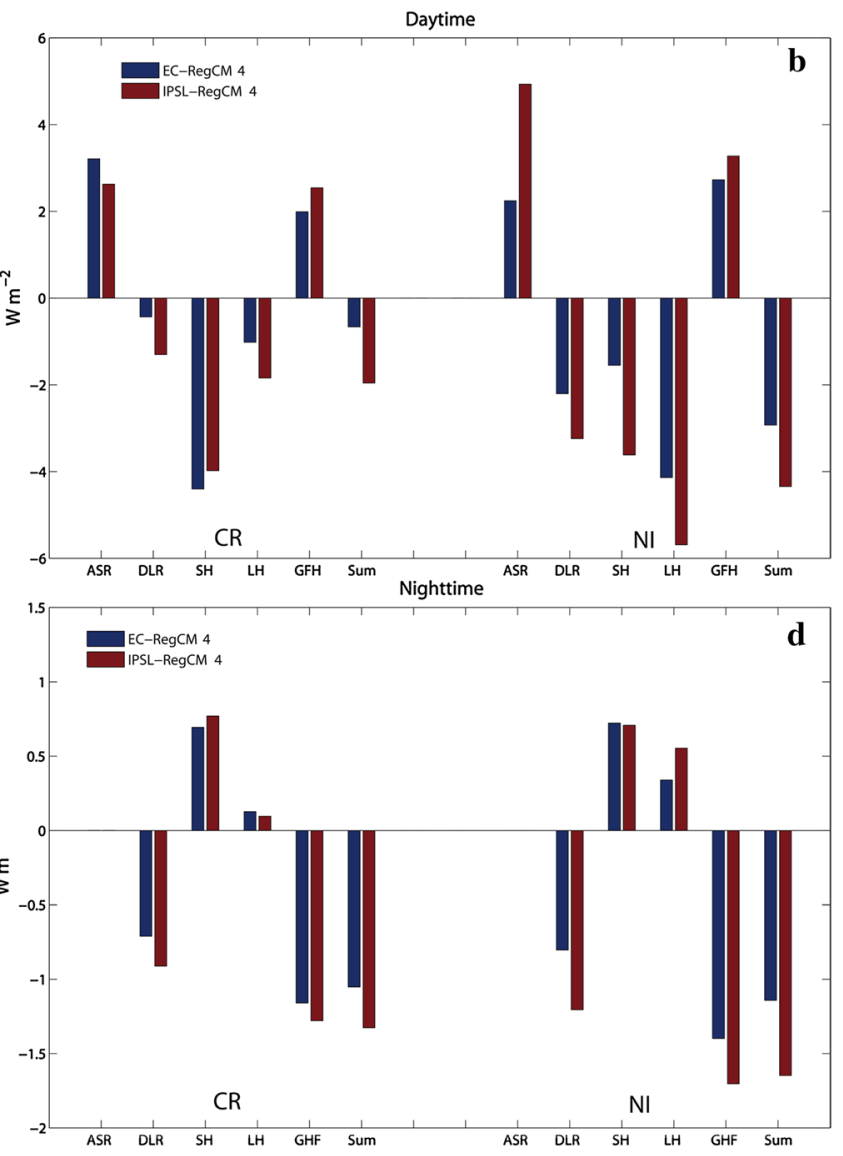

Sum means the sum of all components. Three components including $\mathrm{SH}, \mathrm{LH}$ and GHF are multiplied by -1 for convenient comparison. Note that daytime (nighttime) is set to UTC 06 (UTC 18) for NEC and EC, UTC 09 (UTC 21) for CR and NI

where the latent heat flux is strongly limited by moisture (Pitman et al. 2011).

In order to further investigate the possible mechanism responsible for the inter-model differences in temperature responses, the region $\left(30-35^{\circ} \mathrm{N}, 105-110^{\circ} \mathrm{E}\right)$, where a cooling effect for Tmax is simulated in EC-RegCM4 while warming effect in IPSL-RegCM4, is selected. As is shown in Fig. 7, the differences in Tmax responses can mostly explained by diversity changes in the available energy, especially in DLR. These differences are attributed to negative changes in Sum in EC-RegCM4 and positive changes in Sum in IPSL-RegCM4, which result in a decrease in Tmax in EC-RegCM4 and an increase in Tmax in IPSL-RegCM4.

\subsection{Responses of temperature to the extent of LULCC}

The effects of LULCC on climate are largely dependent on the spatial scale of the change (Lawrence and Vandecar 2014; Pitman and Lorenz 2016). However, the relationship 
Fig. 7 As in Fig. 6 but only for Tmax during daytime (UTC 06) over selected areas $\left(30-35^{\circ} \mathrm{N}\right.$, $\left.105-110^{\circ} \mathrm{E}\right)$

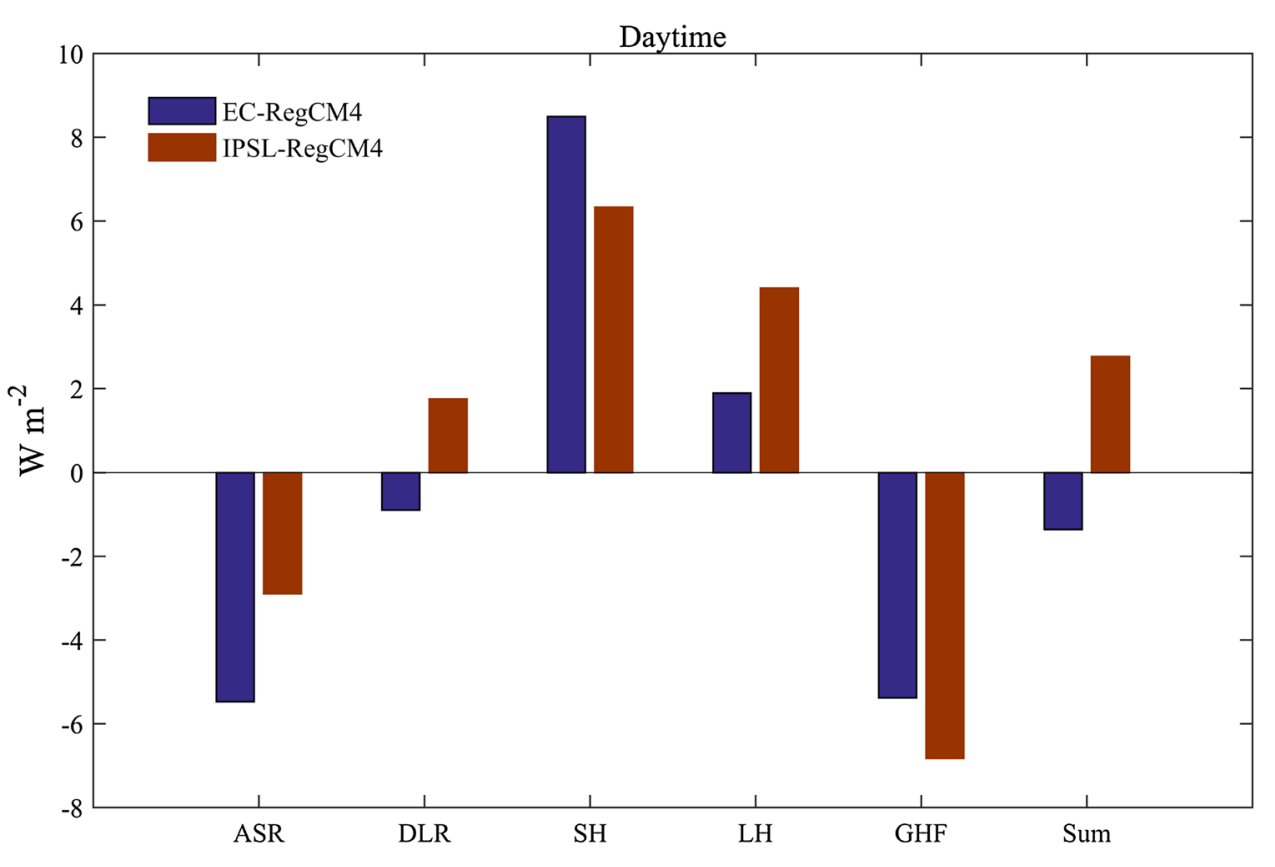

between the temperature responses and the extent of LULCC is not fully understood. Here, the extent of LULCC $(\Delta$ ForestFrac) is defined as the net forest fraction changes simulated between the years 2050 and 1990. To explore this relationship, temperature changes averaged on grid points over the four sub-regions with different degrees of LULCC during the growing season are shown in Fig. 8.

Generally, the more drastic the forest change is, the larger the temperature responses are. However, the relationships between the extent of LULCC and temperature responses are nonlinear, which is consistent with the results in Quesada et al. (2017). For the deforestation areas, the responses of Tmax and Tmin to LULCC over NEC resemble to those over EC, with a decrease in Tmax and an increase in Tmin. However, the changes in temperature are regionally dependent. Compared to Tmax, Tmin is more sensitive to each unit of forest degradation over NEC. However,the sensitivity of Tmin is smaller than that of Tmax over EC when the forest degradation is lower than $10 \%$ while is stronger when the forest degradation is larger than $10 \%$. Moreover, for EC the largest ranges in temperature responses between two models locate the grids with forest change larger than $15 \%$ while occur the grids with forest change between $10 \%$ and $15 \%$ for NEC.

For the afforestation areas, the opposite Tmax responses between CR and NI are found when the forest change larger than 5\%, and Tmin responses to each unit of forest change show same direction over the two regions. Furthermore, the sensitivity of Tmin over CR is larger than that over NI for each unit of forest change, while the sensitivity of Tmax over $\mathrm{NI}$ is stronger when the forest change larger than $10 \%$. Note that different extents of LULCC may have diverse impact on temperature change. For example, opposite Tmax responses are found between the grids with slight LULCC (less than $5 \%$ ) and the grids with substantial LULCC (larger than 5\%) over NI.

\subsection{Contribution of LULCC to future climate change}

Figure 9 shows the ratio of the temperature responses due to LULCC over those due to the increasing GHGs. Similar to the spatial distributions of temperature responses to LULCC, the large ratios exceeding $25 \%$ are mainly located over the areas that experienced conversions between forests and crops. The ratios from IPSL-RegCM4 are smaller than those from EC-RegCM4 by 5-10\% for Tmax and approximately $5 \%$ for Tmin. The ratios for the absolute temperature indices are greater than $30 \%$ over the locations with substantial LULCC (figures not shown). These results indicate that the GHG effects dominant the temperature changes and are modulated locally by the influence of LULCC, particularly for the temperature extremes.

Future LULCC would either amplify or suppress the warming effect induced by $\mathrm{CO} 2$ and ultimately affect the temperature projections over East Asia. The potential role of LULCC in Tmax during summer presents negative contributions over NEC (approximately 3.0-3.6\%), EC (approximately 3.0-10.1\%) and NI (approximately $6.2-7.1 \%$ ), and positive contributions approximately 1.3-2.9\% over CR (Fig. 10). For Tmin, the effects of LULCC enhance the warming effect over deforested areas by $6.3-8.5 \%$ in NEC and $2.8-4.1 \%$ in EC and weaken the increase in Tmin over afforested areas by $4.3-7.0 \%$ in $\mathrm{CR}$ and $7.4-8.3 \%$ in NI. Although the averaged regional 

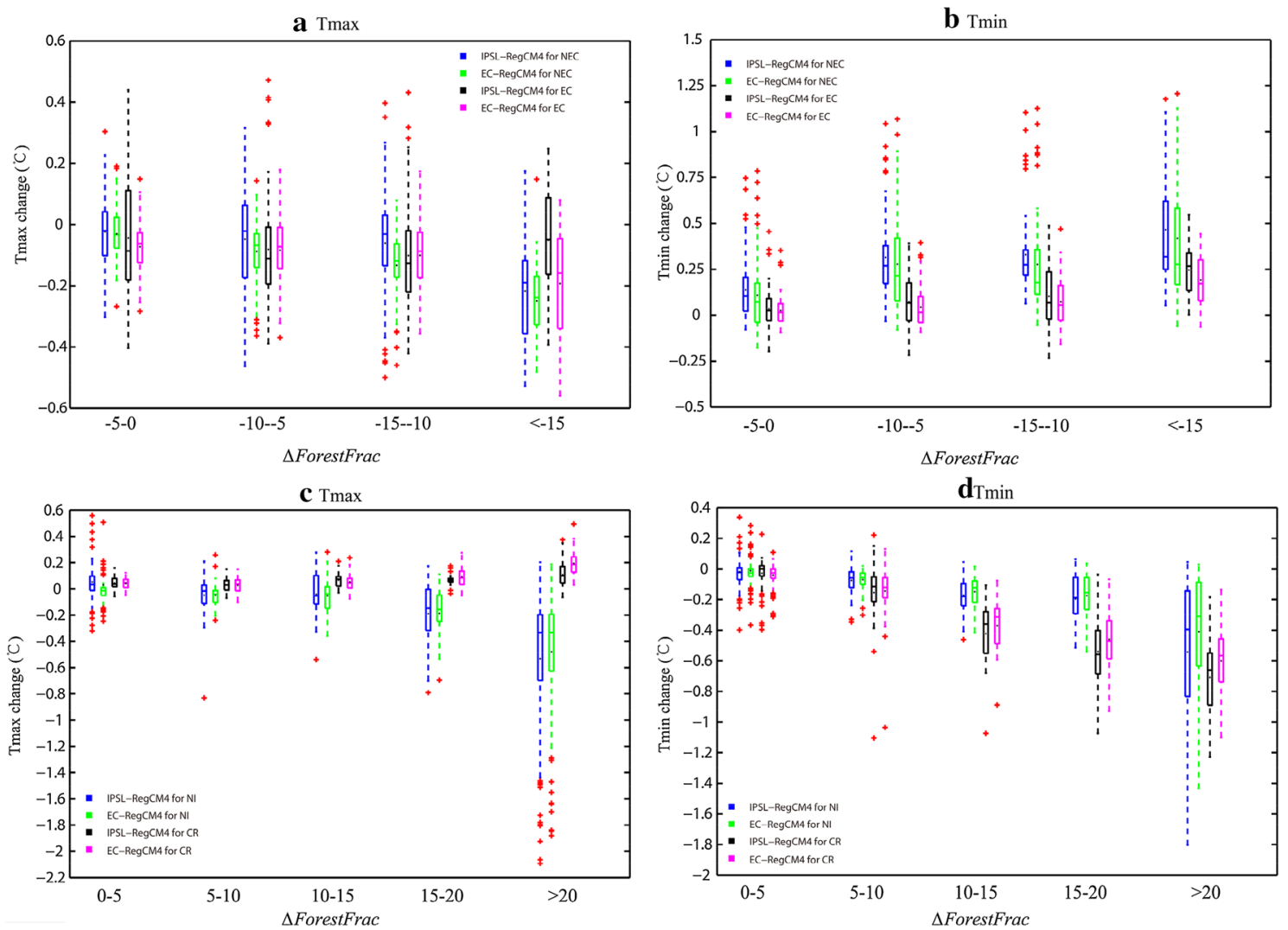

Fig. 8 Box-and-whisker plot for change in Tmax and Tmin with different degrees of LULCC over four sub-regions. On each box, the central mark shows the median, and the bottom and top edges of the box indicate the 25 th and 75 th percentiles, respectively. The circle

contribution is not pronounced, the effects of LULCC can contribute approximately $30 \%$ to the temperature projections at local scales (Supplementary Figure S4). We, therefore, conclude that the impacts of LULCC should be accounted for in detection and attribution studies over East Asia, and neglecting the feedbacks related to LULCC can lead to miscalculated attributions of climate forcing factors to the observed trends in the regional or local climate projections (Pitman et al. 2011).

Driven by different LBCs, the contributions of LULCC to the temperature projections are in similar magnitude between two simulations, except for Tmax over East China. The contribution of LULCC in EC-RegCM4 is three times larger than that in IPSL-RegCM4, which demonstrates the importance of the roles of large-scale atmospheric circulations in the temperature responses to LULCC. Pitman et al. (2011) noted out that increased greenhouse-gas-driven changes in snow and rainfall would affect snow-albedo feedback and the supply of water, which largely control the net impact of LULCC on regional climate though hydrometeorology. They also emphasized that the capacities of climate models to simulate the geographic positions of regional

shows the positions for the mean change and the plus signs indicate the outlier. Different degrees of LULCC means the net forest fraction changes (i.e $\Delta$ ForestFrac $>0 \%, 5 \%, 10 \%, 15 \%$ or $\Delta$ ForestFrac $<0 \%$, $-5 \%<-10 \%,-15 \%)$

climate changes due to increased $\mathrm{CO}_{2}$ are important for capturing the impacts of LULCC in future projections.

\section{Conclusions}

Using RegCM4 driven by IPSL-CM5A and EC-EARTH, two transient climate change simulations are generated over East Asia. The effects of plausible future LULCC on temperature extremes are investigated for the time period of 2039-2060 under the RCP4.5 scenario by using both future and current maps of LULCC in regional climate projections.

The results show that over large areas of East Asia, the influences of LULCC on surface temperature projections are negligible due to the different signs of the impacts of regional LULCC. However, significant changes in temperature are detected over the areas with substantial LULCC, and these changes are characterized by seasonality and regionality. For example, the warming effect induced by forests is simulated for Tmin over CR during winter and persists through May, with the largest change of up to 

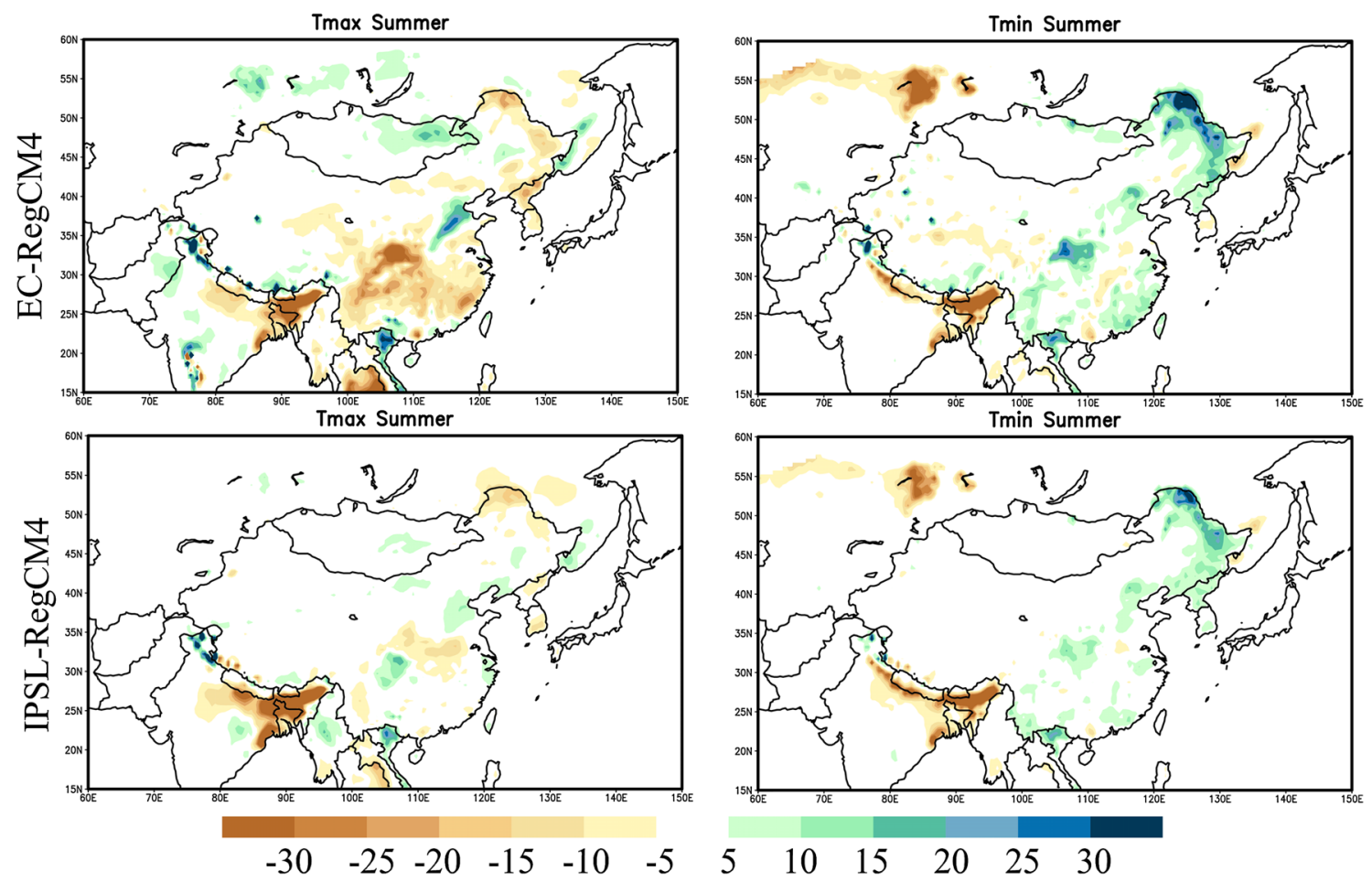

Fig. 9 ratio of the magnitude of Tmax and Tmin induced by LULCC to that by GHGs (unit: \%), which calculated by $\frac{(R C P 45-L 2 A 45)}{(L 2 A 45-R F)} * 100$

$0.14{ }^{\circ} \mathrm{C}$ occurring in March. Afforestation produces a cooling signal in Tmin over NI throughout the year with little seasonal fluctuation. The responses of temperature extremes to LULCC are stronger than those of mean temperature, and LULCC exert more prominent influences on Tmin-related indices than Tmax-related indices. Disagreements in the temperature responses are simulated by the two models during most of the year, particularly in summer. Such disparities indicate that the effects of LULCC on temperature exhibit large uncertainties and are deeply influenced by large-scale atmospheric circulation.

Further analyses suggest that changes in the surface energy flux that are induced by LULCC can control the characteristics of the responses of Tmax and Tmin and lead to diverse sensitivities across regions. Changes in ASR, SH and GHF play dominant roles in determining Tmax over the four subregions, while the sensitivity of Tmin is mainly controlled by GHF. The role of LH over NI cannot be neglected during the day. Our results also show that the large differences in the temperature responses to LULCC between the two models may be attributed to the uncertainty in the available energy responses. The extent of LULCC determines not only the magnitude of the sensitivity of the temperature change but also the sign. Thus, when assessing the impacts of LULCC, the spatial scale of LULCC, the conversion type and the extent of LULCC should all be considered. Moreover, the relative impacts of LULCC to GHG concentrations can reach up to $25 \%$ for Tmax and Tmin over the areas with conversion between forests and crops. The ratio of the effects of LULCC to GHG effects in our study is larger than the ratios calculated in previous studies (Voldoire 2006; Hua et al. 2015), which may be attributed to the various land use scenarios and model sensitivities. Moreover, the effect of LULCC contributes approximately less than $10 \%$ to the regional averaged temperature projections, but it could substantially modify future temperature changes by approximately $30 \%$ at the local scale. These results demonstrate the necessity of including LULCC in future climate projections.

Our results are comparable to the results of previous studies (Feddema et al. 2005; Xu et al. 2015; Li et al. 2017), and aim to provide some insights and clues for understanding the impact of future LULCC on extreme temperature. There are still limitations in the current work. Firstly, the systematic biases in the RegCM4 would affect the model responses to LULCC. Hagos et al. (2014) examined the relationship between the model responses to LULCC and climatologists of the control simulations in Africa, and found that models with wet or dry biases are likely to underestimate the responses due to LULCC. Therefore, the model errors are a potential source of uncertainty for results in our study and the responses to LULCC and related conclusions may be model dependent. Secondly, the diverse changes in Tmax-related indices between the models indicates that the responses to LULCC in an RCM 
Fig. 10 Contribution of future LULCC to future projection with all forcings over four subregions
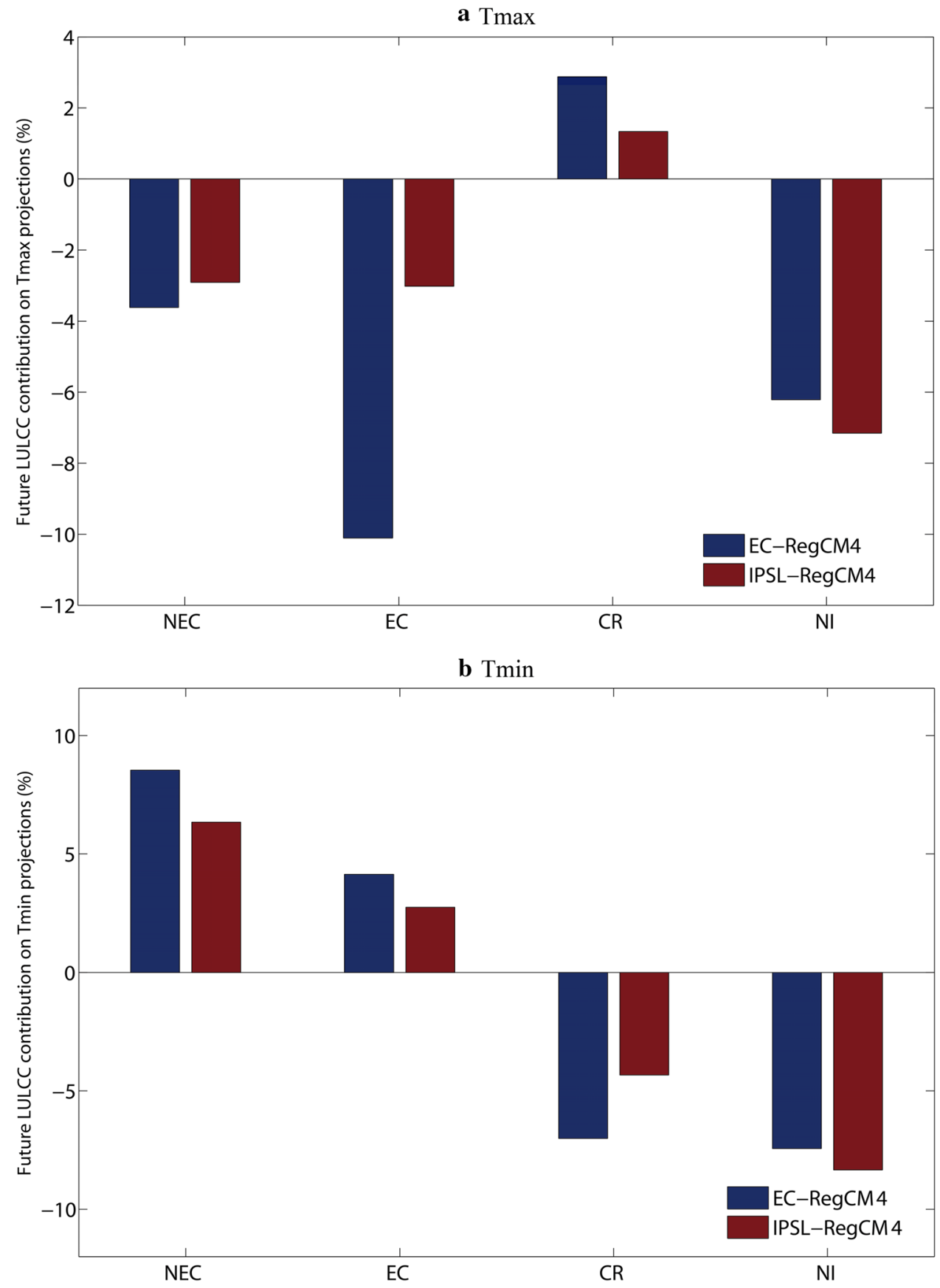

may depend on the LBCs. However, the use of only two GCMs may not be sufficient to assess the impact of LBCs on the role of LULCC in regional climate. Thus, investigating the biogeophysical effect of LULCC over East Asia is new challenge we are facing in future research, and a multi RCM-GCM ensemble matrix driven with multiple scenarios of LUCC is required to fully investigate and understand the effects of LULCC on the climate at different scales.

Acknowledgments The research is found by the National Natural Science Foundation of China $(41505057,41575099)$ and the National key Research and Development Program of China (2017YFA0603803, 2016YFA0600303). This research is also supported by the National Basic Research and Development (973) Program of China (2011CB952004).

Open Access This article is distributed under the terms of the Creative Commons Attribution 4.0 International License (http://creativeco mmons.org/licenses/by/4.0/), which permits unrestricted use, distribution, and reproduction in any medium, provided you give appropriate credit to the original author(s) and the source, provide a link to the Creative Commons license, and indicate if changes were made. 


\section{References}

Alexander LV, Zhang X, Peterson TC et al (2006) Global observed changes in daily climate extremes of temperature and precipitation. J Geophys Res Atmos 111:1042-1063

Alexandru A, Sushama L (2016) Impact of land-use and land-cover changes on CRCM5 climate projections over North America for the twenty-first century. Clim Dyn 47:1197-1209. https://doi. org/10.1007/s00382-015-2896-3

Alkama R, Cescatti A (2016) Biophysical climate impacts of recent changes in global forest cover. Science 351:600

Arora VK, Boer GJ (2010) Uncertainties in the 20th century carbon budget associated with land use change. Global Change Biol $16: 3327-3348$

Bala G, Caldeira K, Wickett M, Phillips TJ, Lobell DB, Delire C, Mirin A (2007) Combined climate and carbon-cycle effects of largescale deforestation. Proc Natl Acad Sci USA 104:6550

Boisier JP, Noblet-Ducoudré N, Pitman AJ et al (2012) Attributing the impacts of land-cover changes in temperate regions on surface temperature and heat fluxes to specific causes: results from the first LUCID set of simulations. J Geophys Res Atmos 117:48-50

Brovkin V, Boysen L, Arora VK et al (2013) Effect of anthropogenic land-use and land-cover changes on climate and land carbon storage in cmip5 projections for the twenty-first century. J Clim 26(18):6859-6881

Christidis N et al (2013) A new HadGEM3-A-based system for attribution of weather- and climate-related extreme events. J Clim $26: 2756-2783$

Claussen M, Brovkin V, Ganopolski A (2001) Biogeophysical versus biogeochemical feedbacks of large-scale land cover change. Geophys Res Lett 28:1011-1014

Dai YJ, Zeng XB, Dickinson RE et al (2003) The common land model. Bull Am Meteorol Soc 84:1013-1024

Davin EL, Nobletducoudré ND (2010) Climatic impact of global-scale deforestation: radiative versus nonradiative processes. J Clim 23:97

De Nobletducoudré N, Boisier JP, Piterman A, Bonan GB, Brovkin V, Cruz F, Delire C, Gayler V, van den Hurk B, Lawrence PJ (2012) Determining robust impacts of land-use-induced land cover changes on surface climate over North America and Eurasia: results from the first set of LUCID experiments. J Clim 25:3261-3281

Dufresne JL et al (2013) Climate change projections using the IPSLCM5 earth system model: from CMIP3 to CMIP5. Clim Dyn 40:2123-2165

Emanuel KA (1991) A scheme for representing cumulus convection in large-scale models. J Atmos Sci 48:2313-2329

Feddema JJ, Oleson KW, Bonan GB, Mearns LO, Buja LE, Meehl GA, Washington WM (2005) The importance of land-cover change in simulating future climates. Science 310:1674-1678

Findell KL, Shevliakova E, Milly PCD, Stouffer RJ (2007) Modeled impact of anthropogenic land cover change on climate. J Clim 20:3621-3634. https://doi.org/10.1175/jcli4185.1

Findell KL, Pitman AJ, England MH, Pegion PJ (2008) Regional and global impacts of land cover change and sea surface temperature anomalies. J Clim 22:3248-3269

Findell KL, Berg A, Gentine P et al (2017) The impact of anthropogenic land use and land cover change on regional climate extremes. Nat Commun. https://doi.org/10.1038/s41467-01701038-w

Fu CB, Wang SY, Xiong Z, Gutowski W, Lee DK, McGregor J, Sato Y, Kato H, Kim H, Suh MS (2005) Regional climate model intercomparison project for Asia. Bull Am Meteorol Soc 86:257-266
Fu CB, Yuan HL (2001) An virtual numerical experiment to understand the impacts of recovering natural vegetation on the summer climate and environmental conditions in East Asia. Sci Bull 46:1199-1203

Gao XJ, Pal JS, Giorgi F (2006) Projected changes in mean and extreme precipitation over the Mediterranean region from a high resolution double nested RCM simulation. Geophys Res Lett $33: 155-170$

Giorgi F, Coppola E, Solmon F et al (2012) RegCM4: model description and preliminary tests over multiple CORDEX domains. Clim Res 52:7-29

Goldewijk KK (2001) Estimating global land use change over the past 300 years: the HYDE database. Global Biogeochem Cycles $15: 417-433$

Govindasamy B, Duffy PB, Caldeira K (2001) Land use changes and northern hemisphere cooling. Geophys Res Lett 28:291-294

Hagos S, Leung LR, Xue Y, Boone A, de Sales F, Neupane N, Huang M, Yoon JH (2014) Assessment of uncertainties in the response of the African monsoon precipitation to land use changesimulated by a regional model. Clim Dyn 43:2765-2775. https://doi. org/10.1007/s00382-014-2092-x

Hazeleger W, Severijns C, Semmler T, Ştefănescu S, Yang S, Wang XL, Wyser K, Dutra E, Baldasano JM, Bintanja R (2010) ECearth: a seamless earth-system prediction approach in action. Bull Am Meteorol Soc 91:1357-1363

Holtslag AAM, Boville BA (1993) Local versus nonlocal boundarylayer diffusion in a global climate model. J Clim 6:1825-1842

Hua WJ, Chen HS, Sun S, Zhou L (2015) Assessing climatic impacts of future land use and land cover change projected with the CanESM2 model. Int J Climatol 35:3661-3675

Hui PH, Tang JP, Wang SY, Niu XR, Zong PS, Dong X (2017) Climate change projections over China using regional climate models forced by two CMIP5 global models. Part I: evaluation of historical simulations. Int J Climatol. https://doi.org/10.1002/joc.5351

Hui P, Tang J, Wang S, Niu X, Zong P, Dong X (2018) Climate change projections over China using regional climate models forced by two CMIP5 global models. Part II: projections of future climate. Int J Climatol. https://doi.org/10.1002/joc.5409

Hurtt GC, Chini LP, Frolking S et al (2011) Harmonization of land-use scenarios for the period 1500-2100: 600 years of global gridded annual land-use transitions, wood harvest, and resulting secondary lands. Clim Change 109:117-161. https://doi.org/10.1007/s1058 4-011-0153-2

Juang JY, Katul G, Siqueira M, Stoy P, Novick K (2007) Separating the effects of albedo from eco-physiological changes on surface temperature along a successionachronosequence in the southeastern United States. Geophys Res Lett 34:L21408

Kiehl JT, Hack JJ, Bonan GB, Boville BA, Briegleb BP, Williamson DL, Rasch PJ (1993) Description of the ncar community climate model (ccm3). In: NCAR Technical Note pp 55-60

Lawrence D, Vandecar K (2014) Effects of tropical deforestation on climate and agriculture. Nat Clim Change 5:27-36

Lawrence DM, Hurtt GC, Arneth A, Brovkin V, Calvin KV, Jones AD, Jones CD, Lawrence PJ, de Noblet-Ducoudré N, Pongratz J (2016) The Land Use Model Intercomparison Project (LUMIP) contribution to CMIP6:rationale and experimental design. Geosci Model Dev 9:2973-2998

Li X, Chen HS, Liao H, Hua WJ, Ma HD, Li X, Gao CJ, Zhu SG (2017) Potential effects of land cover change on temperature extremes over Eurasia: current versus historical experiments. Int J Climatol 37:59-74

Matthews HD, Weaver AJ, Eby M, Meissner KJ (2003) Radiative forcing of climate by historical land cover change. Geophys Res Lett 30(2):1055. https://doi.org/10.1029/2002GL016098

Niu XR, Wang SY, Tang JP et al (2015) Multi-model ensemble projection of precipitation in eastern China under the A1B emission 
scenario. J Geophys Res Atmos 120:9965-9980. https://doi. org/10.1002/2015JD023853

Notaro M, Chen G, Liu Z (2011) Vegetation feedbacks to climate in the global monsoon regions. J Clim 24:5740-5756

Oleson KW, Niu GY, Yang ZL, Lawrence DM, Thornton PE, Lawrence PJ, Stöckli R, Dickinson RE, Bonan GB, Levis S (2008) Improvements to the community land model and their impact on the hydrological cycle. J Geophys Res. https://doi.org/10.1029/2007J G000563

Pal JS, Small EE, Eltahir EAB (2000) Simulation of regional-scale water and energy budgets: representation of subgrid cloud and precipitation processes within RegCM. J Geophys Res Atmos 105:29579-29594

Pal JS, Giorgi F, Bi XQ, Elguindi N, Solmon F, Gao XJ, Rauscher SA, Francisco R, Zakey A, Winter J (2007) Regional climate modeling for the developing world: the ICTP RegCM3 and RegCNET. Bull Am Meteorol Soc 88:1395-1409

Peng SS, Piao S, Zeng Z, Ciais P, Zhou L, Li LZ, Myneni RB, Yin Y, Zeng H (2014) Afforestation in China cools local land surface temperature. Proc Natl Acad Sci USA 111(8):2915-2919

Pitman AJ, Lorenz R (2016) Scale dependence of the simulated impact of Amazonian deforestation on regional climate. Environ Res Lett 11:094025

Pitman AJ, de Noblet-Ducoudré N, Cruz FT, Davin EL, Bonan GB, Brovkin V, Claussen M, Delire C, Ganzeveld L, Gayler V (2009) Uncertainties in climate responses to past land cover change: first results from the LUCID intercomparison study. Geophys Res Lett 36:171-183

Pitman AJ, Avila FB, Abramowitz G, Wang YP, Phipps SJ, de NobletDucoudré N (2011) Importance of background climate in determining impact of land-cover change on regional climate. Nat Clim Change 1:472. https://doi.org/10.1038/nclimate1294

Quesada B, Arneth A, de Noblet-Ducoudré N (2017) Atmospheric, radiative and hydrologic effects of future land-use and land-cover changes: a global and multi-model climate picture. J Geophys Res Atmos 122(10):5113-5131
Saini R, Wang GL, Yu M, Kim JH (2015) Comparison of RCMs and GCMs projections of summer precipitation in West Africa. Geophys Res Atmos 120:3679-3699

Strack JE, Pielke RA, Steyaert LT, Knox RG (2008) Sensitivity of June near-surface temperatures and precipitation in the eastern United States to historical land cover changes since European settlement. Water Resour Res 44:2183-2188

Voldoire A (2006) Quantifying the impact of future land-use changes against increases in GHG concentrations. Geophys Res Lett 33:211-220

Wang ZL, Huang X, Ding AJ (2018) Dome effect of black carbon and its key influencing factors: a one-dimensional modelling study. Atmos Chem Phys 18:2821-2834

Wen QH, Zhang X, Xu Y, Wang B (2013) Detecting human influence on extreme temperatures in China. Geophys Res Lett 40:1171-1176

Xu Z, Mahmood R, Yang ZL, Fu C, Su H (2015) Investigating diurnal and seasonal climatic response to land use and land cover change over monsoon Asia with the community earth system model. J Geophys Res Atmos 120:1137-1152

Yu M, Wang GL (2014) Impact of bias correction of lateral boundary conditions on regional climate projections in West Africa. Clim Dyn 42:2521-2538

Zhang H, Gao X, Li Y (2009) Climate impacts of land-use change in China and its uncertainty in a global model simulation. Clim Dyn 32:473-494

Zhao M, Pitman AJ (2002) The regional scale impact of land cover change simulated with a climate model. Int J Climatol 22:271-290

Zhou L, Dickinson RE, Tian Y, Vose RS, Dai Y (2007) Impact of vegetation removal and soil aridation on diurnal temperature range in a semiarid region: application to the Sahel. Proc Natl Acad Sci USA 104:17937

Zou L, Zhou T (2016) A regional ocean-atmosphere coupled model developed for CORDEX East Asia: assessment of Asian summer monsoon simulation. Clim Dyn 47:3627-3640 